\title{
Acute Liver Failure in Cuban Children
}

\author{
César E. Silverio MD, Chleo Y. Smithen-Romany MD, Norma I. Hondal MD, Hetzel O. Díaz MD, Marlen I. Castellanos MD PhD, \\ Oramis Sosa MD
}

\begin{abstract}
INTRODUCTION Acute liver failure is rare in pediatric patients and is one of the most challenging medical emergencies due to its prognostic and therapeutic implications. The best scientific evidence worldwide comes from multicenter studies in developed countries. In Cuba, there are no prior studies of this disorder in children.
\end{abstract}

OBJECTIVES Describe the main clinical features of Cuban children treated at a national referral center for acute liver failure, as defined by recognized diagnostic criteria for pediatric patients.

METHODS A case series study was conducted comprising patients diagnosed with acute liver failure treated from 2005 to 2011 in the hepatology and liver transplant service at Havana's William Soler University Children's Hospital. Variables were age group, etiology of acute liver failure, grade of hepatic encephalopathy, blood chemistry variables, and clinical outcome (whether or not spontaneous recovery of liver function occurred). Associations between variables were assessed using contingency tables, and case fatality was calculated, as well as relative risk with its $95 \%$ confidence interval. The Mann-Whitney $U$ test was used to compare means of laboratory test results.

\section{INTRODUCTION}

Although rare in pediatrics, acute liver failure (ALF) is one of the most challenging medical emergencies because of its multisystemic nature, its short natural history, the need for multidisciplinary supportive interventions, and the medical training required to accurately determine prognosis and make better use of orthotopic liver transplantation as a definitive treatment.[1,2]

Acute liver failure was first defined by Trey and Davidson as a potentially reversible condition caused by severe liver damage accompanied by encephalopathy within eight weeks of symptom onset and in the absence of preexisting liver disease.[3] Many definitions have been used over the years, taking into consideration the average time between symptom onset and appearance of hepatic encephalopathy. These classifications have been designed primarily to estimate prognosis, and no consensus has yet been reached on the best definition of ALF.[4]

According to the American Association of Liver Diseases, the most widely accepted definition of acute liver failure in adults is the presence of altered coagulation, expressed by an international normalized ratio (INR) $\geq 1.5$ and some degree of altered mental status (encephalopathy) in a patient without preexisting cirrhosis of the liver, with no more than 26 weeks between appearance of these alterations and onset of jaundice or other signs or symptoms of liver disease.[5] Children, especially infants, do not exhibit classic signs of encephalopathy, and it may not manifest clinically until advanced stages of the disease. Bhaduri and Mieli-Vergani defined ALF in children as a rare multisystemic disease that causes severe damage to liver function, with or without encephalopathy, and occurs in association with hepatocellular necrosis in patients without known chronic liver disease.[6]
RESULTS Median age of the 31 patients studied (14 boys and 17 girls) was 24 months (range 1-180). Time between symptom onset and diagnosis of acute liver failure was 25.1 days (SD 16.8). Infection was the most common etiology, present in $61.3 \%$ of cases (19/31); nonhepatotropic viruses, especially cytomegalovirus, predominated in infants. Spontaneous recovery occurred in 15 patients $(48.4 \%), 3$ $(9.7 \%)$ received transplants, and 13 died, for a case fatality of $41.9 \%$. Outcome was not associated with etiology $(p=0.106)$, but was statistically associated with degree of hepatic encephalopathy $(p<0.01)$ : $77.8 \%$ of patients $(7 / 9)$ with grades III-IV encephalopathy died, for a relative risk of $4.0(95 \% \mathrm{Cl} 1.15-13.8)$, versus $11.1 \%$ (1/9) with grade II or less encephalopathy. Cholesterol levels were significantly lower in patients who failed to recover spontaneously $(p<0.01)$.

CONCLUSIONS Patients' clinical characteristics in this case series were similar to those described in developed countries. The fact that nonhepatotropic viruses (basically, cytomegalovirus in infants) are the main cause of acute liver failure in Cuban children calls for further epidemiologic study and identification of local underlying determinants of this phenomenon.

KEYWORDS Acute liver failure/etiology, transplants, infections, cytomegalovirus, children, pediatrics, Cuba

The Pediatric Acute Liver Failure Study Group, createdin conjunction with the USNIH in 24 sites (in the USA, Canada, and UK) used an updated definition of ALF in children from birth to age 18 years that includes a series of clinical and biochemical indicators:[7]

- biochemical evidence of acute liver injury

- no prior chronic liver disease

- coagulopathy of hepatic origin (prothrombin time PT>20 seconds; or INR $\geq 1.5$ not corrected by vitamin $\mathrm{K}$ with clinical encephalopathy; or INR $>2.0$, with or without encephalopathy)

ALF's clinical manifestations are common to all causes, although there may be subtle differences, such as the characteristic prodromes in viral hepatitides (low-grade or high fever, nausea, vomiting and abdominal pain), or a history of exposure to toxic substances or drugs. In general, children with ALF are previously healthy; they often exhibit rapidly worsening jaundice, accompanied by abdominal pain, anorexia, fever, and vomiting. In infants, jaundice may be mild or absent, and the predominant symptoms are hypoglycemia, vomiting, refusal to eat, irritability, changes in sleep patterns, and seizures. Hepatic encephalopathy is the complex of neuropsychiatric alterations stemming from altered liver function. It is functional in nature and potentially reversible; has a broad spectrum of severity, ranging from mild sensory alteration to coma; and can be of late onset in infants and small children. Altered coagulation is present in all patients, clinically manifested by ecchymosis, petechiae, bleeding at puncture sites, and gastrointestinal or other internal organ hemorrhage. Gastrointestinal hemorrhage can be observed in up to $70 \%$ of pediatric ALF patients.[8]

The specific cause of ALF is not established in up to $50 \%$ of cases, but etiology varies according to the child's age. Metabolic liver 
diseases and nonhepatotropic viral infections are more common in neonates and infants, whereas drug-induced hepatitis, hepatotropic viral hepatitides, autoimmune disorders and Wilson disease are seen more often in older children and adolescents.[7,9]

The clinical course of ALF is related to its etiology. Cases in which the condition is caused by paracetamol or hepatitis A virus have a better prognosis than those caused by seronegative hepatitis. ALF survival is also related to severity of hepatic encephalopathy, as well as to disease duration prior to onset of encephalopathy. [8] Biochemistry parameters considered predictive factors include aminotransferase, albumin, bilirubin and creatinine levels; however, published findings vary.[9-12] No single criterion accurately predicts mortality or is universally applicable to all ALF patients with different etiologies.[13]

ALF incidence is relatively low; historically, reports have come from experiences in isolated centers or general reviews conducted primarily in Canada, USA and Europe, with the limitations associated with using adult ALF diagnostic criteria for children.[7] In Cuba, a dearth of national reports makes it impossible to have a general perspective on earlier work with these patients, leading to the assumption that the cumulative experience also comes from isolated centers.

In 2004, Cuba's Ministry of Public Health (MINSAP) decided to prepare the ground for performance of pediatric liver transplants, with the creation of the hepatology and liver transplant service at the William Soler University Children's Hospital (HPUWS) in Havana[14] as the national referral center for Cuban children with ALF. Its primary mission is to guarantee early, specialized and comprehensive care for children with terminal liver diseases who are transplant candidates.

The aim of this study is to describe the main characteristics and clinical outcomes of a case series of pediatric ALF patients (per established pediatric diagnostic criteria) treated at HPUWS.

\section{METHODS}

Type of study and patients A retrospective case series study was conducted in the HPUWS hepatology and liver transplant service, using administrative data from its first six years in operation (January 2005-December 2011). The universe consisted of all patients admitted to the HPUWS ICU with a presumptive diagnosis of liver failure during the study period and assessed using the ALF treatment protocol of the HPUWS hepatology and liver transplant service's organizational and procedural manual (in force since 2005, latest update 2010). The protocol includes initial assessment and general and specific therapeutic strategies for ALF, according to the Working Group report of the Second World Congress of Pediatric Gastroenterology, Hepatology, and Nutrition, adapted from Squires.[15,16] Patients selected met the diagnostic and treatment criteria set out in the manual in force the year they were hospitalized.

Inclusion criteria Eligible patients were all children aged 29 days to 18 years meeting established ALF criteria for: evidence of liver damage in the absence of prior known chronic liver disease; altered coagulation, expressed as PT >15 seconds with encephalopathy; or PT>20 seconds with or without encephalopathy-all this within eight weeks of onset of clinical symptoms and signs of liver disease. Encephalopathy was not a criterion for diagnosis of ALF in infants.

\section{Variables}

Demographic variables were age group (29 days to 11 months and 29 days; $1-5$ years; and 6-18 years) and sex (female/male).

Hepatic encephalopathy was classified per the Study Group recommendations:[7]

Grades I-II: inconsolable crying; inattention to tasks; "not acting like self," according to parents; normal reflexes or hyperreflexic Grade III: somnolence, stupor, combativeness, hyperreflexia Grade IV: coma [rousable with painful stimuli (IVa) or nonresponsive (IVb)], reflexes absent, decerebration or decortication

ALF etiology was classified as: infectious (viral), metabolic, autoimmune (per International Autoimmune Hepatitis Group criteria),[17] and other (e.g., toxic; hematologic, oncologic and vascular).

Clinical outcome was interpreted with respect to recovery of liver function, in two groups:

- Spontaneous recovery: Patient survived with life support and progressed satisfactorily without transplantation

- Failure to recover: Patient failed to recover liver function and progress satisfactorily despite life support (with two subcategories: transplantation, and death from ALF without transplantation)

Liver-specific tests (hematological and biochemical) These included (reference values in parentheses) PT ( $\leq 15$ seconds), alanine aminotransferase $(<50 \mathrm{IU} / \mathrm{L})$, aspartate aminotransferase $(<50 \mathrm{IU} / \mathrm{L})$, bilirubin $(<17 \mu \mathrm{mol} / \mathrm{L})$, albumin (35-52 g/L), and cholesterol (2.8-6 $\mathrm{mmol} / \mathrm{L}$ ). Glycemia was not analyzed, since it is of limited use as a predictor because it is affected by therapy and by ALF cause.

Data collection Patients with a diagnosis of ALF on admission and/or discharge were selected from HPUWS medical records. Clinical histories were reviewed and information on each variable was entered into a database.

The next three sections describe standard HPUWS procedures that generated the data used in this study.

Virology Studies to detect cytomegalovirus (CMV), herpes simplex virus, Epstein Barr virus (EBV), and hepatitis $B$ and $C$ viruses in blood (viremia) are done through amplification or polymerase chain reaction (PCR) at the national virology reference laboratory in Havana's Pedro Kourí Tropical Medicine Institute (IPK). In the case of hepatitis A and E and dengue viruses, serum IgM antibodies are detected. Cases with a clinical picture and biochemistry parameters suggestive of viral hepatitis with negative viral markers and no prior history of exposure to toxins and drugs are classified as seronegative hepatitis.[18,19]

Tests for metabolic disease Blood and urine samples are analyzed in the specialized laboratories of the National Medical Genetics Center (CNGM) to identify congenital errors of metabolism (alpha 1 antitrypsin deficiency, galactosemia, tyrosinemia, Wilson disease, neonatal hemochromatosis, fatty acid beta-oxidation disorders and other enzyme deficiencies). According to causal inference guidelines, toxic causes (carbon tetrachloride, halothane, and potentially hepatotoxic herbs and drugs) are excluded in the absence of immediate exposure or exposure up to six months prior to ALF onset.[20]

Liver-specific tests To assess the degree of inflammation, injury, and function these are conducted in the HPUWS clinical laboratory according to established procedures. 
Data processing and analysis Variables were entered and processed in an SPSS 21.0 database. Infants were excluded from the encephalopathy analysis, since ALF onset is usually late and difficult to assess. Data analysis used the mean, standard deviation (SD), confidence interval for the mean, and the median for quantitative variables, and absolute numbers and percentages for qualitative variables. In all analyses, a $5 \%$ significance level was used.

Case fatality was calculated as ALF deaths/total ALF patients $x$ 100. To assess association between etiology and outcome, causes were grouped as infectious and noninfectious. Encephalopathies were also grouped into grades $0-I I$ and III-IV. Associations were assessed through contingency tables and calculation of the Mantel-Haenszel chi square and Fisher exact test, as appropriate (with significance levels). Relative risk $(R R)$ and $95 \%$ confidence intervals were determined. The Mann-Whitney $U$ test was used to compare independent sample means.

Ethics All identifying information was kept confidential and patient anonymity was protected. The study was approved by the HPUWS ethics committee.

\section{RESULTS}

A total of 31 patients with ALF were admitted during the study period: 14 male $(45.2 \%)$ and 17 female $(54.8 \%)$, with a median age of 24 months (range: 1-180). Mean time between symptom onset and ALF diagnosis was 25.1 days (SD 16.8).

Infants were the largest age group (41.9\%); children aged 1-5 years, the smallest $(25.8 \%)$ (Table 1$)$. Infectious causes were the most frequent, present in 19 cases $(61.3 \%)$; the majority nonhepatotropic viruses; while metabolic, autoimmune and other causes were observed in 12 patients (38.7\%) (Table 1).
Infectious and metabolic causes predominated in infants. Other causes included hemophagocytic syndrome (a condition resulting from a pathological immune activation with excessive inflammation, characterized by fever, cytopenias, splenomegaly, hemophagocytosis, hypertriglyceridemia and/or hypofibrinogenemia) in three patients; in one child, ALF was secondary to an idiosyncratic response to propylthiouracil and, in another, a child aged $>5$ years, it was a result of non-Hodgkin lymphoma. CMV ranked first among infectious causes, present exclusively in children aged $<1$ year, followed by seronegative hepatitis, which was equally distributed between the groups aged $1-5$ and $>5$ years. Metabolic causes of ALF were congenital hypopituitarism (2 male infants, aged 32 and 60 days, respectively, with micropenis, hypoglycemia, jaundice, abnormally low cortisol levels and ALF criterion manifested by hepatic coagulopathy that failed to resolve with parenteral vitamin $\mathrm{K}$ ), followed by fatty-acid beta-oxidation disorder and pyruvic carboxylase deficiency, in a single patient each (Table 1).

Among cases of infectious etiology, 12 children (63.1\%) failed to recover spontaneously, principally when the cause was CMV (autopsy corroborated) or seronegative hepatitis. Among cases with metabolic causes, analysis revealed that the only patient with pyruvic carboxylase deficiency died, and that two of the three patients with autoimmune hepatitis spontaneously recovered. A peculiar form of autoimmune hepatitis known as Coombs-positive giant-cell hepatitis was also observed in one patient who died. No significant association was observed between etiology (infectious vs. noninfectious) and outcome $(p=0.106)$ (Table 2$)$.

Spontaneous recovery from ALF was observed in 15 children (48.4\%). Surviving patients included 5 of 13 infants $(38.5 \%), 3$ of 8 children aged $1-5 y e a r s ~(37.5 \%)$, and 7 of 10 aged $>5$ years $(70 \%)$. Survival (without transplantation) was lowest for infectious causes (7/19), compared with 2 of 3 patients with autoimmune causes and 3 of 4 patients with metabolic causes.
Table 1: Pediatric ALF by cause and age $(n=31)$

\begin{tabular}{|c|c|c|c|c|c|}
\hline \multirow[b]{2}{*}{ Cause } & \multicolumn{3}{|c|}{ Age group } & \multirow[b]{2}{*}{$\mathbf{n}$} & \multirow[b]{2}{*}{$\%$} \\
\hline & $\begin{array}{l}29 \text { days-11 } \\
\text { months } \\
29 \text { days }\end{array}$ & $\begin{array}{c}1-5 \\
\text { years }\end{array}$ & $\begin{array}{c}6-18 \\
\text { years }\end{array}$ & & \\
\hline Infectious & 9 & 4 & 6 & 19 & 61.3 \\
\hline Cytomegalovirus & 8 & 0 & 0 & 8 & 42.1 \\
\hline Seronegative hepatitis & 0 & 3 & 3 & 6 & 31.6 \\
\hline Herpes simplex virus & 1 & 1 & 0 & 2 & 10.5 \\
\hline Epstein-Barr virus & 0 & 0 & 1 & 1 & 5.3 \\
\hline Hepatitis $\mathrm{C}$ virus & 0 & 0 & 1 & 1 & 5.3 \\
\hline Dengue virus & 0 & 0 & 1 & 1 & 5.3 \\
\hline Metabolic & 3 & 1 & 0 & 4 & 12.9 \\
\hline Congenital hypopituitarism & 2 & 0 & 0 & 2 & 50.0 \\
\hline Fatty acid $B$ oxidation disorder & 0 & 1 & 0 & 1 & 25.0 \\
\hline Pyruvic carboxylase deficiency & 1 & 0 & 0 & 1 & 25.0 \\
\hline Autoimmune hepatitis & 0 & 1 & 2 & 3 & 9.7 \\
\hline Other & 1 & 2 & 2 & 5 & 16.1 \\
\hline Hemophagocytic disorder & 1 & 2 & 0 & 3 & 60.0 \\
\hline Toxic (propylthiouracil) & 0 & 0 & 1 & 1 & 20.0 \\
\hline Non-Hodgkin lymphoma & 0 & 0 & 1 & 1 & 20.0 \\
\hline TOTAL & 13 & 8 & 10 & 31 & 100.0 \\
\hline$\%$ & 41.9 & 25.8 & 32.3 & 100 & \\
\hline
\end{tabular}

ALF: acute liver failure
Table 3 presents data for the 16 patients who did not recover spontaneously. Half of these were infants, withmost cases due to infectious causes $(75 \%)$. Case fatality was $41.9 \%(13 / 31)$. A total of 3 patients received transplants: 2 (aged 2 and 10 years) with ALF due to seronegative hepatitis and 1 (aged 5 years) due to herpes simplex.

Grade of encephalopathy was assessed in 18 patients aged 1-15 years; 9 presented grades III-IV hepatic encephalopathy, and an equal number of patients, grades I-II or none. Analysis of this indicator in terms of disease outcome showed that patients with higher grades of encephalopathy (III-IV) were at highest risk of failure to spontaneously recover (RR 4.0, 95\% Cl 1.15-13.8, p <0.01) (Table 4).

In liver-specific test results, mean ASAT values exceeded ALAT values (Table 5). The highest values for aminotransferases, bilirubin, and prothrombin time were seen in the group that fared the worst-that is, patients who failed to recover spontaneously. Lower albumin and cholesterol values were also observed in this group. Despite these numerical differences, the only statistically significant variable was cholesterol, which was substantially lower in the 3 transplant recipients and in 11 of the 13 who died. 
Table 2: Pediatric ALF outcome by cause $(n=31)$

\begin{tabular}{|c|c|c|c|c|c|}
\hline \multirow{3}{*}{ Cause* } & \multicolumn{4}{|c|}{ Outcome } & \multirow{3}{*}{ Total } \\
\hline & \multicolumn{2}{|c|}{$\begin{array}{c}\text { Spontaneous } \\
\text { recovery } \\
(n=15)\end{array}$} & \multicolumn{2}{|c|}{$\begin{array}{l}\text { No spontaneous } \\
\text { recovery* } \\
(n=16)\end{array}$} & \\
\hline & $n$ & $\%$ & $n$ & $\%$ & \\
\hline Infectious & 7 & & 12 & & 19 \\
\hline Cytomegalovirus & 2 & 25.0 & 6 & 75.0 & 8 \\
\hline $\begin{array}{l}\text { Seronegative } \\
\text { hepatitis }\end{array}$ & 2 & 33.3 & 4 & 66.7 & 6 \\
\hline Herpes simplex virus & 1 & 50.0 & 1 & 50.0 & 2 \\
\hline Epstein-Barr virus & 1 & 100.0 & 0 & 0.0 & 1 \\
\hline Hepatitis C virus & 0 & 0.0 & 1 & 100.0 & 1 \\
\hline Dengue virus & 1 & 100.0 & 0 & 0.0 & 1 \\
\hline Noninfectious & 8 & & 4 & & 12 \\
\hline Metabolic & 3 & & 1 & & 4 \\
\hline $\begin{array}{l}\text { Congenital } \\
\text { hypopituitarism }\end{array}$ & 2 & 100.0 & 0 & 0.0 & 2 \\
\hline $\begin{array}{l}\text { Fatty acid oxidation } \\
\text { disorder }\end{array}$ & 1 & 100.0 & 0 & 0.0 & 1 \\
\hline $\begin{array}{l}\text { Pyruvic-carboxylase } \\
\text { deficiency }\end{array}$ & 0 & 0.0 & 1 & 100.0 & 1 \\
\hline Autoimmune hepatitis & 2 & 66.7 & 1 & 33.3 & 3 \\
\hline Other & 3 & 60.0 & 2 & 40.0 & 5 \\
\hline
\end{tabular}

$\%$ calculated by row

*includes transplants and deaths

$p=0.106$ (Mantel-Haenszel chi square) with causes regrouped as infectious and noninfectious

ALF: acute liver failure

Table 3: Pediatric ALF patients who failed to recover spontaneously, by cause $(n=16)$

\begin{tabular}{|c|c|c|c|c|c|}
\hline \multirow[b]{2}{*}{ Cause } & \multicolumn{3}{|c|}{ Age group } & \multirow[b]{2}{*}{ Total } & \multirow[b]{2}{*}{$\%$} \\
\hline & $\begin{array}{c}29 \text { days to } \\
<1 \text { year }\end{array}$ & $\begin{array}{c}1-5 \\
\text { years }\end{array}$ & $\begin{array}{c}>5 \\
\text { years }\end{array}$ & & \\
\hline Infectious & 6 & 3 & 3 & 12 & 75.0 \\
\hline Cytomegalovirus & 6 & 0 & 0 & 6 & 50.0 \\
\hline $\begin{array}{l}\text { Seronegative } \\
\text { hepatitis }\end{array}$ & 0 & $2^{*}$ & $2^{*}$ & 4 & 33.4 \\
\hline Herpes simplex virus & 0 & $1^{*}$ & 0 & 1 & 8.3 \\
\hline Hepatitis $\mathrm{C}$ virus & 0 & 0 & 1 & 1 & 8.3 \\
\hline $\begin{array}{l}\text { Metabolic } \\
\text { Pyruvic carboxylase } \\
\text { deficiency }\end{array}$ & 1 & 0 & 0 & 1 & 6.2 \\
\hline Autoimmune hepatitis & 0 & 1 & 0 & 1 & 6.2 \\
\hline $\begin{array}{l}\text { Hemophagocytic } \\
\text { syndrome }\end{array}$ & 1 & 1 & 0 & 2 & 12.6 \\
\hline Total & 8 & 5 & 3 & 16 & 100.0 \\
\hline$\%$ & 50.0 & 31.3 & 18.7 & 100 & \\
\hline
\end{tabular}

3 patients transplanted: 2 with seronegative hepatitis (aged 2 and10 years) and 1 with herpes simplex (aged 5 years)

ALF: acute liver failure

\section{DISCUSSION}

Clinical, biochemical and epidemiologic characterization of ALFmakes it possible to tailor needed testing and therapy in a timely manner. Causation is a factor to consider in ALF progression, since it dictates specific actions for managing the disease and may provide prognostic information.[21,22] Small sample size likely accounts for the lack of statistical significance observed for the association between etiology and outcome in our study.
The causes most frequently encountered in our series are similar to those described in developed countries, where predominant causes are nonhepatotropic viral hepatitides and seronegative hepatitis, followed by metabolic hepatitides. This series differs, however, in its high frequency of CMV infection, which is the most interesting finding of this study, since few ALF cases caused by CMV are reported in the literature (where herpes simplex is referred to as the most common cause). In our study, nonhepatotropic viruses (herpes viruses, including EBV and CMV, enterovirus and adenovirus) were the main infectious causes in infants under one year.The epidemiologic pattern observed is interesting, and future investigations are proposed to shed light on this finding, emphasizing immunologic status and perinatal history, as suggested by other authors.[7,11,23-25]

Herpes virus seroprevalence studies in Cuban children in recent decades report greater frequency of exposure to CMV than to herpes simplex: $67.6 \%$ vs. $46.2 \%$.[26] While this does not imply active disease, it is an indicator of high CMV exposure. In a study of 555 sera from patients with a presumptive diagnosis of infectious mononucleosis (2006-2011), Correa found $80.2 \%$ immunoglobin-G positivity for CMV and $64.3 \%$ for EBV. Active primary or recurrent infection was demonstrated in $53.2 \%$ of cases, most frequently with EBV. Most primary infections were detected in patients aged $<18$ years, with CMV infections most frequent.[27] Although Correa's data do not necessarily support a higher prevalence of CMV disease, they do show the high frequency of exposure to this virus in the population aged $<18$ years. More research is needed, therefore, to elucidate the role of CMV in ALF genesis.

Seronegative hepatitis presents in a manner similar to that of acute viral hepatitis, but no virus is detected; it is the most common etiology in developed countries, at approximately 45\%.[16] In the UK, Lee posited seronegative hepatitis as the leading cause of ALF in children aged >1 month.[11] In our series, it was the second leading cause, which coincides with findings by Squires and Black in US studies conducted in the first decade of this century. $[7,23,28]$

ALF caused by hepatitis A, B, and C viruses (hepatotropic viruses) is reported mainly in adults; the highest incidence in children occurs in developing countries, hepatitis $A$ and $E$ being the most common causes.[22,29,30] In a multicenter study in 2001-2002 that included Argentina, Brazil, Chile, Colombia, Costa Rica and Mexico, hepatitis A virus was reported as the leading cause of ALF (43\% of cases).[31] There are isolated reports from Argentina and Chile ( $32 \%$ and $37 \%$ of ALF, respectively) caused by hepatitis A.[32,33] In Brazil, the proportion of ALF caused by hepatitis A varies geographically from $39 \%$ to $82.6 \%$.[34,35]

We detected no hepatitis A, B, or E virus in our series. According to Cuban morbidity reports, incidence of acute viral hepatitis $A$, $B$, and $C$ decreased over the study period, and, apart from isolated cases, no epidemic outbreaks of hepatitis A occurred.[36] It is worth noting that, while hepatitis $B$ virus plays a significant role in other countries, universal hepatitis $B$ vaccination of the entire population aged $<25$ years by Cuba's National Vaccination Program has led to a decline in incidence and prevalence of this disease over the past 15 years.[36] No cases of acute hepatitis B in children have been reported in Cuba since 2006.[37] Acute hepatitis $\mathrm{C}$, though less frequent, generally occurs in children aged $>5$ years, $[7,23]$ consistent with our finding that the single case of hepatitis $\mathrm{C}$ was in the oldest pediatric age group. 
Table 4: ALF outcome by grade of hepatic encephalopathy $(n=18)$

\begin{tabular}{|c|c|c|c|c|}
\hline \multirow{3}{*}{$\begin{array}{l}\text { Grade of hepatic } \\
\text { encephalopathy } \\
\text { (n) }\end{array}$} & \multicolumn{4}{|c|}{ Outcome $^{a}$} \\
\hline & \multicolumn{2}{|c|}{$\begin{array}{l}\text { Spontaneous } \\
\text { recovery } \\
(n=10)\end{array}$} & \multicolumn{2}{|c|}{$\begin{array}{l}\text { No spontaneous } \\
\text { recovery } \\
(n=8)\end{array}$} \\
\hline & $n$ & $\%$ & $n$ & $\%$ \\
\hline $0(3)$ & 2 & 66.7 & 1 & 33.3 \\
\hline I (3) & 3 & 100.0 & 0 & 0.0 \\
\hline II (3) & 3 & 100.0 & 0 & 0.0 \\
\hline III (7) & 2 & 28.6 & 5 & 71.4 \\
\hline IV (2) & 0 & 0.0 & 2 & 100.0 \\
\hline \multicolumn{5}{|l|}{ Grade groups ${ }^{b}$} \\
\hline $0-I I(9)$ & 8 & 88.9 & 1 & 11.1 \\
\hline III-IV (9) & 2 & 22.2 & 7 & 77.8 \\
\hline
\end{tabular}

${ }^{a}$ excluding 13 infants, \% calculated by row

${ }^{\mathrm{b} p}<0.01$ (Fisher exact test), RR 4.0 (Cl 95\% 1.15-13.8)

ALF: acute liver failure

Table 5: ALF outcome by liver-specific test concentrations $(n=31)$

\begin{tabular}{|c|c|c|c|}
\hline \multirow[b]{2}{*}{ Test } & \multicolumn{2}{|c|}{ Outcome } & \multirow{2}{*}{ p Value* } \\
\hline & $\begin{array}{l}\text { Spontaneous } \\
\text { recovery } \\
(n=15)\end{array}$ & $\begin{array}{c}\text { No spontaneous } \\
\text { recovery } \\
(n=16)\end{array}$ & \\
\hline ALAT (IU/L) & 215.5 (SD 181.5) & 303.6 (SD 291.1) & 0.406 \\
\hline ASAT (IU/L) & 480.0 (SD 299.2) & 546.2 (SD 224.8) & 0.678 \\
\hline $\begin{array}{l}\text { Serum } \\
\text { bilirubin }(\mu \mathrm{mol} / \mathrm{L})\end{array}$ & 211.2 (SD 140.7) & 250.4 (SD 126.4) & 0.377 \\
\hline PT (sec) & 38.5 (SD 16.9) & 48.0 (SD 16.9) & 0.356 \\
\hline Serum albumin $(g / L)$ & 32.2 (SD 5.5) & 28.9 (SD 9.3) & 0.200 \\
\hline $\begin{array}{l}\text { Cholesterol } \\
(\mathrm{mmol} / \mathrm{L})\end{array}$ & 3.8 (SD 2.6) & $1.3(\mathrm{SD} 0.8)$ & 0.001 \\
\hline
\end{tabular}

*Differences between means among groups (Mann-Whitney $U$ test)

ALAT: alanine aminotransferase (normal range $<50 \mathrm{IU} / \mathrm{L}$ )

ALF: acute liver failure

ASAT: aspartate aminotransferase (normal range $<50 \mathrm{IU} / \mathrm{L}$ )

$\mathrm{PT}$ : prothrombin time (reference value $\leq 15 \mathrm{sec}$ )

Our finding that metabolic causes ranked second in infants is consistent with reports that these causes follow infectious causes in order of frequency, at approximately $20 \%$, primarily in neonates and infants.[23] Prevalence of metabolic diseases varies geographically; it is higher in Europe, Canada and the USA, and lower in Asia and South America.[8,9,22] An interesting study in Portugal of children aged $<2$ years, admitted for ALF in 19892011 , showed that $52 \%$ suffered from metabolic disorders, the most frequent of which were hereditary.[38]

Wilson disease is a rare cause of ALF, generally reported in children aged $>5$ years and adolescents; it has a poor prognosis. $[8,39,40]$ The fact that it was not encountered in this study may reflect its rarity and the small size of our series. In Cuba, the most common hepatic presentation of Wilson disease in children and adolescents is hypertransaminasemia (55\%), while prolonged acute hepatitis, hepatic cirrhosis and chronic hepatitis are less common $(9.5 \%, 7.9 \%$ and $6.3 \%$, respectively); the absence of ALF in Wilson disease cases is interesting and may be due to small numbers seen (only 62 in 25 years).[41] Because it is a recessive autosomal disease, its frequency is not high; its reported worldwide prevalence is on the order of $1 / 30,000$ population. A 37-year study conducted in the United Kingdom identified only 57 patients with this disease, $47.3 \%$ of whom developed ALF.[42]
Autoimmune hepatitis is an important and potentially treatable cause of ALF. In this study, it was the third most frequent group of causes, consistent with findings of other authors.[7,11,24,39,43]

Spontaneous recovery was within the expected range, since variable frequencies of $30 \%-60 \%$ have been reported. $[7,11,13,44,45]$ The introduction of coagulation testing - a key element for diagnosing this disease in children-markedly improved patient prognosis, inter alia because of timely admission to intensive care. Coagulopathy is an independent risk factor for mortality or need for liver transplantation; hence, the importance of including it among diagnostic criteria for ALF.[46]

A high percentage of patients with CMV infection-all of them infants_failed to recover spontaneously. Infants with ALF caused by CMV generally have the poorest outcomes,[47] although our series was too small to be informative on this point, since even the infectious versus noninfectious difference was nonsignficant. ALF with seronegative hepatitis also has a poor prognosis and low rate of spontaneous recovery.[45] Our finding that the majority of patients with ALF with these etiologies died or required liver transplantation is consistent with reports elsewhere.[45,47]

ALF cases with metabolic causes (congenital hypopituitarism and fatty acid beta-oxidation disorder) improved with specific medical treatment for these disorders. Prognosis for this group of disorders, which should be suspected from the outset in children aged $<1$ year, depends largely on early diagnosis and administration of specific therapy. $[8,38,48]$ There is no specific treatment for pyruvic carboxylase deficiency, and it can also affect other organs, which was the case of the patient with this disorder who died.

Two of the three patients who developed ALF as a result of autoimmune hepatitis progressed to spontaneous recovery with immunosuppressant therapy. The patient who did not recover was diagnosed with Coombs-positive giant cell hepatitis, a rare form of autoimmune hepatitis that responds poorly to treatment.[49,50]

According to Squires, spontaneous recovery is more likely in patients without hepatic encephalopathy.[23] Similarly, children with grades I and II encephalopathy on admission have a greater likelihood of surviving without liver transplantation than those with grades III and IV.[8,11] This was also seen in our series, where most patients without encephalopathy and those with grades I and II encephalopathy recovered without need for transplantation.

Biochemical parameters are correlated with the degree of hepatic necrosis and progression, but their predictive ability is unreliable. In general, we observed aminotransferase-level increases to 5-10 times normal value, with a greater increase in ASAT than in ALAT, which is expected in ALF because of extensive liver cell necrosis. $[8,11,51]$ Rivera-Penera observed years ago that patients with ALF who died had a higher serum bilirubin peak and lower ALAT values than those who recovered without transplantation.[52] Later, Lee also found that those with higher serum bilirubin levels, longer PT and lower aminotransferase levels died or required transplantation, while there were no significant differences in outcome for other biochemical parameters, such as blood albumin, ASAT, and alkaline phosphatase.[11]

This study assessed cholesterol because it is a parameter that reflects liver synthetic function.[51] Of all indicators, this was 
the one that showed the greatest outcome difference; it was significantly lower in patients who failed to recover spontaneously, which could be due to the severity of liver failure. There are few reports of cholesterol as a prognostic indicator for ALF, and its interpretation has limitations, since it derives from retrospective studies.[53,54] Unlike the rest of the indicators of liver synthetic function (coagulation, albumin, and bilirubin proteins), cholesterol is not very susceptible to variation with therapy (use of blood products, dialysis, etc.),[5] and therefore may be a more valid reflection of liver function capacity. Further exploration of its usefulness in assessing ALF is therefore needed.

Spontaneous recovery patterns we observed-overall survival without transplantation close to $50 \%$, higher in older children and lower with infectious causes, albeit nonsignficantly-are similar to those reported by other authors in larger series in developed countries such as the USA and France. Miloh and Suchy (USA), for example, reported figures on the order of $43 \%$ for undetermined causes, $44 \%$ for metabolic causes, and $41 \%$ for ALF induced by drugs unrelated to paracetamol.[55] Sundaram (USA) found survival of $60 \%$ in infants aged $<90$ days;[24] however, years earlier, Durand (France) had reported $24 \%$ survival in children aged $<1$ year.[47] In Portugal, survival in children aged $<2$ years was greater in ALF of metabolic origin than of infectious origin.[38] Survival in children aged $>3$ years was higher, around 54\%, in Canada and the USA.[23] Specialized care in a transplant center for this type of patient and improved care for critical patients foster better outcomes.

The main limitation of this study, besides its small size, is that it stems from a case series and reflects only patterns in the patients treated, with no intention to generalize to other contexts. However, this report is one of the few publications on the topic in Cuba, in fact the first of its kind in the country. This experience contributes to our understanding of pediatric ALF and to the formulation of new hypotheses to shed light on the causal and prognostic factors related to this rare but fatal condition.

\section{CONCLUSIONS}

Further research on the epidemiology and local determinants of ALF is needed to explain the predominance of prior infection with hepatotropic viruses, especially CMV in infants.

\section{ACKNOWLEDGMENTS}

The authors wish to thank the national virology reference laboratory at IPK for its collaboration in the processing of samples from the patients in the study and the CNGM for its participation in conducting the metabolic and genetic studies. -1 .

\section{REFERENCES}

1. Craig DG, Lee A, Hayes PC, Simpson KJ. Review article: the current management of acute liver failure. Alimentary Pharmacol Ther. 2010 Feb 1;31(3):345-58

2. Devictor $D$, Tissieres $P$, Afanetti M, Debray D Acute liver failure in children. Clin Res Hepatol Gastroenterol. 2011 Jun;35(6-7):430-7.

3. Trey C, Davidson CS. The management of fulminant hepatic failure. Prog Liver Dis. 1970;3:282-98.

4. Wlodzimirow KA, Eslami S, Abu-Hanna A, Nieuwoudt M, Chamuleau RA. Systematic review: acute liver failure-one disease, more than 40 definitions. Aliment Pharmacol Ther. 2012 Jun;35(11):1245-56

5. Lee WM, Stravitz RT, Larson AM. Introduction to the revised American Association for the Study of Liver Diseases Position Paper on acute liver failure 2011. Hepatology. 2012 Mar;55(3):965-7.

6. Bhaduri BR, Mieli-Vergani G. Fulminant hepatic failure: pediatric aspects. Semin Liver Dis. 1996 Nov;16(4):349-55

7. Squires R. Acute liver failure in children. Semin Liver Dis. 2008;28:153-66.

8. Alonso E, Squires R, Whitington P. Acute Liver Failure in Children. In: Suchy FJ, Sokol RJ, Balistreri WF, editors. Liver Disease in Children. 3rd ed. Cambridge: Cambridge University Press; 2007. p.71-96

9. Dhawan A. Etiology and prognosis of acute liver failure in children. Liver Transpl. 2008 Oct;14 Suppl 2:S80-4.

10. Poddar B, Saigal S, Kumar A, Singh RK, Azim A, Gurjar M, et al. Factors associated with outcome in acute liver failure in an intensive care unit. Indian J Gastroenterol. 2013 May;32(3):172-8.

11. Lee WS, McKiernan P, Kelly DA. Etiology, outcome and prognostic indicators of childhood fulminant hepatic failure in the United Kingdom. J Pediatr Gastroenterol Nutr. 2005 May;40(5):575-81.

12. Lu BR, Gralla J, Liu E, Dobyns EL, Narkewicz MR, Sokol RJ. Evaluation of a scoring system for assessing prognosis in pediatric acute liver failure. Clin Gastroenterol Hepatol. 2008 Oct;6(10):1140-5.
13. Sundaram $\mathrm{V}$, Shneider $\mathrm{BL}$, Dhawan $\mathrm{A}, \mathrm{Ng} \mathrm{VL}, \mathrm{Im}$ K, Belle S, et al. King's College Hospital Criteria for non-acetaminophen induced acute liver failure in an international cohort of children. J Pediatr. 2013 Feb;162(2):319-23.

14. Hospital Pediátrico William Soler [Internet]. Havana: Ministry of Public Health (CU); c1999_ 2014 [cited 2014 Feb 13]. Available from: http:// www.sld.cu/sitios/williamsoler/. Spanish.

15. Baker A, Alonso ME Aw MM Ciocca M, Porta G, Rosenthal P. Hepatic failure and liver transplant: Working Group report of the second World Congress of Pediatric Gastroenterology, Hepatology, and Nutrition. J Ped Gastroenterol Nut. 2004 Jun;39 Suppl 2:S632-9.

16. Squires R. Acute liver failure and the pediatric patient. In: Remaley L, McGhee B, Reyes J, Mazariegos G, editors. The Pediatric Transplant Manual. 2nd ed. Pittsburgh: Lexi Comp; 2009. p. 9-29.

17. Alvarez F, Berg PA, Bianchi FB, Bianchi L, BurroughsAK, Cancado EL, et al. International Autoimmune Hepatitis Group Report: review of criteria for diagnosis of autoimmune hepatitis. J Hepatol. 1999 Nov;31(5):929-38

18. Whitington PF, Alonso EM. Fulminant hepatitis in children: evidence for an unidentified hepatitis virus. J Pediatr Gastroenterol Nutr. 2001 Nov;33(5):529-36

19. Delic D, Mitrovic N, Spurnic AR, SvirtlihNS, Babic JS. Epidemiological characteristics and clinical manifestations of acute non-A-E hepatitis. Vojnosanit Pregl. 2010 Nov;67(11):903-9.

20. Polson J, Lee WM. American Association for the Study of Liver Diseases Position Paper: The management of acute liver failure. Hepatology. 2005 May;41(5):1179-97.

21. Rustom N, Bost M, Cour-Andlauer F, Lachaux A, Brunet AS, Boillot $O$, et al. Effect of molecular adsorbents recirculating system treatment in children with acute liver failure caused by Wilson disease. J Pediatr Gastroenterol Nutr. 2014 Feb;58(2):160-4.

22. Pediatric Gastroenterology Chapter of Indian Academy of Pediatrics; Bhatia V, Bavdekar
A, Yachha SK; Indian Academy of Pediatrics. Management of acute liver failure in infants and children: consensus statement of the pediatric gastroenterology chapter, Indian academy of pediatrics. Indian Pediatr. 2013 May 8;50(5):477-82.

23. Squires RH Jr, Shneider BL, Bucuvalas J, Alonso E, Sokol RJ, Narkewicz MR, et al. Acute liver failure in children: the first 348 patients in the pediatric acute liver failure study group. J Pediatr. 2006 May;148(5):652-8.

24. Sundaram SS, Alonso EM, Narkewicz MR, Zhang S, Squires RH; Pediatric Acute Liver Failure Study Group. Characterization and outcomes of young infants with acute liver failure. J Pediatr. 2011 Nov;159(5):813-8

25. Yu YD, Park GC, Park PJ, Choi YI, Hwang S, Song $\mathrm{GW}$, et al. Cytomegalovirus infection-associated fulminant hepatitis in an immunocompetent adult requiring emergency living-donor liver transplantation: report of a case. Surg Today. 2013 Apr;43(4):424-8.

26. Acosta C, Pérez X, García R. Presencia de anticuerpos IgG al virus de la rubeola, virus herpes simple y citomegalovirus en niños cubanos. Bioquimia. 2000 Jan-Mar;25(1):10-2. Spanish.

27. Correa C, Kourí V, Pérez L, Alemán Y, Soto $Y$ Álvarez A, et al. Infecciones por virus de EpsteinBarr y citomegalovirus en pacientes con síndrome mononucleósico. Panorama Cuba y Salud. 2013 Sep-Dec;8(3):15-20. Spanish.

28. Black DD. The continuing challenge of "indeterminate" acute liver failure in children. J Pediatr. 2009 Dec;155(6):769-70.

29. Bravo LC, Gregorio GV, Shafi F, Bock HL, Boud ville I, Liu Y, et al. Etiology, incidence and outcomes of acute hepatic failure in 0-18 year old Filipino children. Southeast Asian J Trop Med Public Health. 2012 May;43(3):764-72.

30. Kaur S, Kumar P, Kumar V, Sarin SK, Kumar A. Etiology and prognostic factors of acute liver failure in children. Indian Pediatr. 2013 Jul:50(7):677-9.

31. Ciocca M, Moreira-Silva SF, Alegría S, Galoppo MC, Ruttiman R, Porta G, et al. Hepatitis A as an 
etiologic agent of acute liver failure in Latin America. Pediatr Infect Dis J. 2007 Aug;26(8):711-5.

32. Ciocca M, Ramonet M, Cuarterolo M, López S, Cernadas C, Álvarez F. Prognostic factors in paediatric acute liver failure. Arch Dis Child. 2008 Jan;93(1):48-51.

33. Uribe M, Buckel E, Ferrario M, Godoy J, Blanco A, Hunter B, et al. Epidemiology and results of liver transplantation for acute liver failure in Chile. Transpl Proc. 2003 Nov;35(7):2511-2.

34. Ferreira CT, Vieira SM, Kieling CO, Silveira TR. Hepatitis A acute liver failure: follow-up of paediatric patients in southern Brazil. J Viral Hepat. 2008 Oct;15Suppl 2:66-8.

35. Moreira-Silva SF, Frauches DO, Almeida AL, Mendonça HF, Pereira FE. Acute liver failure in children: observations in Vitoria, Espirito Santo State, Brazil. Rev Soc Bras Med Trop. 2002 Sep-Oct;35(5):483-6.

36. National Health Statistics and Medical Records Division (CU). Estadísticas de Salud [Internet]. Havana: Ministry of Public Health (CU); c2014. Series de Tiempo de Morbilidad. Cuba 19702010; 2011 Dec [cited 2013 May 20]. Available from: http://files.sld.cu/dne/files/2011/12/serie -de-morbilidad-1970-2010.pdf. Spanish.

37. Castañeda C. Hepatitis B crónica en la infancia. In: Hernández JCSM, editor. Hepatología 2006. Havana: Ediciones CIMEQ; 2006. p. 231-43. Spanish.

38. Brett A, Carvalho L, Garcia P, Diogo L, Gonçalves I. Acute liver failure in under two year-olds -are there markers of metabolic disease on admission? Ann Hepatol. 2013 SepOct;12(5):791-6.

39. Cakir B, Kirbas I, Demirhan B, Tarhan NC, Bozkurt A, Ozcay $F$, et al. Fulminant hepatic failure in children: etiology, histopathology and MDCT findings. Eur J Radiol. 2009 Nov;72(2):327-34.

40. Devarbhavi H, Singh R, Adarsh CK, Sheth K, Kiran R, Patil M. Factors that predict mortality in children with Wilson disease associated acute liver failure and comparison of Wilson disease specific prognostic indices. J Gastroenterol Hepatol. 2014 Feb;29(2):380-6.

41. Fragoso T, Garcia E, Escobar MP, Castañeda C Pomar F, Gra B, et al. Clinical presentation and diagnosis of Wilson disease in Cuban children and adolescents. J Pediatr Gastroenterol Nutr. 2004;39:S138-9.

42. Dhawan A, Taylor RM, Cheeseman P, De Silva P, Katsiyiannakis L, Mieli-Vergani G. Wilson's
Disease in Children: 37-Year Experience and Revised King's Score for Liver Transpl. Liver Transpl. 2005 Apr;11(4):441-8.

43. Mieli-Vergani G, Vergani D. Paediatric autoimmune liver disease. Arch Dis Childhood. 2013 Dec;98(12):1012-7.

44 Latif N Mehmood K Risk factors for fulminant hepatic failure and their relation with outcome in children. J Pak Med Assoc. 2010 Mar;60(3):175-8.

45. Rajanayagam J, Coman D, Cartwright $D$, Lewindon PJ. Pediatric acute liver failure: etiology, outcomes, and the role of serial pediatric end-stage liver disease scores. Pediatr Transplant. 2013 Jun;17(4):362-8.

46. Lu BR, Zhang S, Narkewicz MR, Belle SH, Squires RH, Sokol RJ, et al. Evaluation of the liver injury unit scoring system to predict survival in a multinational study of pediatric acute liver failure. J Pediatr. 2013 May;162(5):1010-6.

47. Durand P, Debray D, Mandel R, Baujard C Branchereau S, Gauthier F, et al. Acute liver failure in infancy: a 14-year experience of a pediatric liver transplantation center. J Pediatr. 2001 Dec;139(6):871-6.

48. Liu E, MacKenzie T, Dobyns EL, Parikh CR, Karrer FM, Narkewicz MR, et al. Characterization of acute liver failure and development of a continuous risk of death staging system in children. $J$ Hepatol. 2006 Jan;44(1):134-41.

49. Bouguila J, Mabrouk S, Tilouche S, Bakir D, Trabelsi A, Hmila A, et al. Giant cell hepatitis with autoimmune hemolytic anemia in a nine month old infant. World J Hepatol. 2013 Apr 27;5(4):226-9.

50. Bucuvalas J, Yazigi N, Squires RH Jr. Acute liver failure in children. Clin Liver Dis. 2006 Feb;10(1):149-68.

51. Sherlock S, Dooley J. Assessment of Liver Function. In: Sherlock S, Dooley J, editors. Diseases of the Liver and Biliary System. 11th ed. Oxford: Blackwell Publishing; 2002 Jan. p. 19-35.

52. Rivera-Penera T, Moreno J, Skaff C, McDiarmid S, Vargas J, Ament ME. Delayed encephalopathy in fulminant hepatic failure in the pediatric population and the role of liver transplantation. J Ped Gastroenterol Nutr. 1997 Feb;24(2):128-34.

53. Wlodzimirow KA, Eslami S, Abu-Hanna A, Nieuwoudt M, Chamuleau RA. A systematic review on prognostic indicators of acute on chronic liver failure and their predictive value for mortality. Liver Int. 2013 Jan;33(1):40-52.
54. Huo TI, Wu JC, Sheng WY, Chan CY, Hwang SJ, Chen TZ, et al. Prognostic factor analysis of fulminant and subfulminant hepatic failure in an area endemic for hepatitis B. J Gastroenterol Hepatol. 1996 Jun;11(6):560-5.

55. Miloh T, Suchy F. Fulminant Hepatic Failure. In: Elzouki AY, editor. Textbook of Clinical Pediatrics. Springer-Verlag (DE): Ed. Berlin; 2012. p. 2095-100.

\section{THE AUTHORS}

César E. Silverio García (Corresponding author: mcastell@infomed.sld.cu), dual specialist in family medicine and gastroenterology at the hepatology and liver transplant service, William Soler University Children's Hospital (HPUWS), Havana, Cuba.

Chleo Y. Smithen-Romany, pediatrician, hepatology and liver transplant service, HPUWS, Havana, Cuba.

Norma I. Hondal Álvarez, pediatrician, hepatology and liver transplant service, HPUWS, Havana, Cuba.

Hetzel O. Díaz Tartera, dual specialist in family medicine and gastroenterology, hepatology and liver transplant service, HPUWS, Havana, Cuba.

Marlen I. Castellanos Fernández, gastroenterologist with a doctorate in medical sciences. Full professor and senior researcher, biostatistics and clinical research department, Gastroenterology Institute, Havana,Cuba.

Oramis Sosa Palacios, biostatistician, research department, HPU, Havana,Cuba.

Submitted: February 17, 2014

Approved for publication: January 11, 2015 Disclosures: None 